\title{
Simulation and energy integration of distillation tower of a naphtha treatment unit
}

\author{
Ali Jalali ${ }^{1}$, Marzieh Lotfi ${ }^{2, *}$, and Amir H. Mohammadi ${ }^{3, *}$ \\ ${ }^{1}$ Department of Chemical Engineering, Amirkabir University of Technology (Tehran Polytechnic), Tehran, Iran \\ ${ }^{2}$ Department of Chemical Engineering, Science and Research Branch, Islamic Azad University, Tehran, Iran \\ ${ }^{3}$ Discipline of Chemical Engineering, School of Engineering, University of KwaZulu-Natal, Howard College Campus, \\ King George V Avenue, Durban 4041, South Africa
}

Received: 15 June 2018 / Accepted: 21 September 2018

\begin{abstract}
Energy optimization is of vital importance especially in oil, gas and petrochemical industries. Distillation column with high energy consumption is one of the most common equipment in the aforementioned industries. Thus, it is important to revise the projection of initial process, reduce energy consumption and recover some of used energy. In this work, we studied energy optimization of a naphtha treating unit in a petrochemical company using Aspen HYSYS software. For energy optimization, feed temperature was changed to a satisfactory temperature $\left(47^{\circ} \mathrm{C}\right)$ for condensation of overhead steam distillation. Feed was used as a cooling fluid in the heat exchanger before the main condenser. According to outcome, $644.11 \mathrm{MW}$ of energy was recovered and approximately $53 \%$ less energy was used in the air conditioner. Feed was injected in tower with higher temperature $\left(212^{\circ} \mathrm{C}\right)$ because of preheating. This reduces consumed energy up to approximately $63 \%$ by reducing the entering flow rate of reboiler.
\end{abstract}

\section{Introduction}

Considering the energy consumption growth in the world, energy optimization has become a main objective in developed countries. In the early 80 s, ascending oil cost which is controlling energy market caused further studies for energy optimization in order to reduce the development cost in industrial countries and later in semi-industrial countries (Amidpour and Polley, 1997). Simultaneously environmental considerations have been noticed and lead to different methods of environment protection and new restrictions to industrial plants. Industry owners are more eager to benefit from direct effects of energy optimization rather indirect profits of environmental factors (Polley and Heggs, 1999; Tjoe and Linnhoff, 1986).

Distillation towers are widely used in petrochemical industries as a tool for separation process (Geankoplis et al., 2018). Distillation is a common process that has a high rank in term of energy consumption. Hence, distillation is an expensive method of separation which affects the plant profitability. The injected thermal energy in reboiler is consumed to vaporize heavy component in liquid phase. However, energy is wasted to supply backflow (Rossiter

\footnotetext{
* Corresponding authors: marzieh.lotfi@srbiau.ac.ir; amir_h_mohammadi@yahoo.com
}

et al., 1993). There are some ideas about energy optimization in distillation towers (Kiran and Jana, 2015; Skiborowski et al., 2018; Tarjani et al., 2018). Thermal integration is one of the newest (Jana, 2017; Zheng et al., 2017). It is important to optimize the distillation process because of the energy consumption growth and ascending energy cost. Steam, hot oil or furnace are economical and available heat sources for energy (Gundersen, 2000; Umeda et al., 1979).

In recent decades due to the ascending energy cost, energy optimization is of vital importance in petrochemical plants (Furman et al., 2017; Gong et al., 2017). Nonoptimized energy consumption will cause a lot of problems including environmental problems. Hence, the environmental organizations are against it (Morgan, 1992). With the efforts of experts a lot of ways were suggested to solve this dilemma. For example, using the wasted energy in processes. In this regard, several concepts were introduced and applied. One of these concepts is process integration (Manan et al., 2017; Natori, 1992).

Process integration is a new concept that was introduced in the 80s and used widespread in the 90s. It is used for checking an especial part of systematic activities. These activities are related to process design (Snoek and Tjoe, 1992). Energy optimization is one of the most important factors in a petrochemical unit, as mentioned earlier 


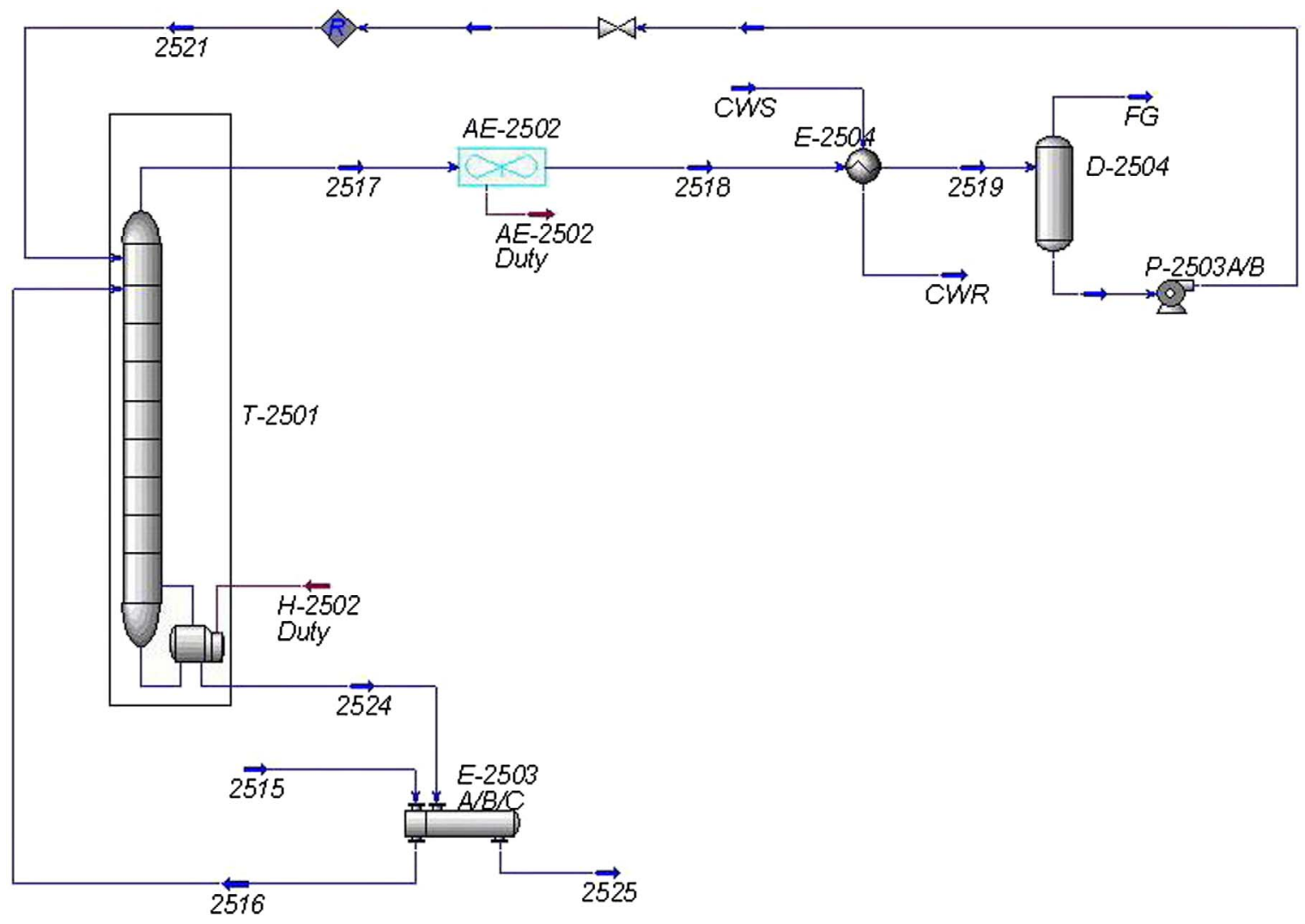

Fig. 1. Schematic of naphtha treating unit simulation (using Aspen HYSYS) for Nuri Petrochemical Plant.

(Zhao et al., 2017). By determining the lowest amount of heat and cooling energy needed in a process, saved energy is also determined. Hence, thermal integration is very important in economy of designs (Gerberich and Seaman, 1994; Yoda and Shibuya, 1995).

First step of thermal integration is studying and calculating the least amount of energy needed from energy sources for heat exchangers network. This energy is supplied by several streams (Biegler et al., 1997).

As pointed out earlier, optimizing the energy consumed in distillation towers increases the plants profitability. Hence, it is necessity to first compare the energy consumed to a standard and then interpret the difference in all levels. To optimize energy in distillation towers there are a lot of ideas in the related articles (Portha et al., 2010). Generally, these methods are divided into three main categories (Avenier et al., 2016; Gerberich and Seaman, 1994; Yoda and Shibuya, 1995).

1. Methods requiring small funds.

2. Methods requiring regular funds.

3. Methods requiring major funds.

Methods requiring small funds are useful in functioning operational units. Methods requiring regular to major funds are usable in new units after technical and economical reviews (Yoda and Shibuya, 1995). In an operational distillation unit, it is possible to optimize energy by performing advanced repair plans with small funds. In every operational unit and new design, it is possible to optimize energy by adding optimized insulation systems and moving feed's plate with regular funds (Gerberich and Seaman, 1994; Yoda and Shibuya, 1995). Instrumentation systems, two-stage condensation and thermal integration are methods used for energy optimization that require major funds (Chang and Shih, 2005; Gerberich and Seaman, 1994; Kamath et al., 2010; Ochoa-Estopier et al., 2014; Shafiee et al., 2018).

In this work, distillation part of a naphtha purification unit in Nuri Petrochemical Company (Iran) was studied. Both equipment units of reboiler and condenser consume a lot of energy (30.6 Megawatts). Tower's reboiler is a furnace that uses gas fuel, which releases pollution in environment. The condenser consumes a lot of energy to condense the vapor. Recycling energy in naphtha purification unit was the main objective of this study which was done by Aspen HYSYS software. Schematic of naphtha treating unit's simulation is shown in Figure 1.

\section{Simulation}

Naphtha distillation tower (T-2501) of Nuri Petrochemical Company (Iran) was simulated. Both units of reboiler and 
Table 1. Details of distillation tower of the naphtha treatment unit.

\begin{tabular}{|c|c|c|c|c|c|}
\hline $\begin{array}{l}\text { Stream No. } \\
\text { Component }\end{array}$ & Mol Wt. & $\begin{array}{c}2521 \\
\text { Wt. } \% \\
\end{array}$ & $\begin{array}{r}2516 \\
\text { Wt. } \% \\
\end{array}$ & $\begin{array}{r}2517 \\
\text { Wt. } \% \\
\end{array}$ & $\begin{array}{r}2524 \\
\text { Wt. } \% \\
\end{array}$ \\
\hline$\overline{\mathrm{H}_{2} \mathrm{~S}}$ & 34.082 & 0.1362 & 0.0092 & 0.1464 & 0 \\
\hline Hydrogen & 2.016 & 0 & 0 & 0 & 0 \\
\hline Methane & 16.043 & 0.0178 & 0.0065 & 0.0283 & 0 \\
\hline Ethane & 30.07 & 0.0488 & 0.0035 & 0.0527 & 0 \\
\hline Propane & 44.097 & 0.0853 & 0.0024 & 0.0858 & 0 \\
\hline n-Butane & 58.123 & 0.192 & 0.0018 & 0.1871 & 0 \\
\hline n-Pentane & 72.15 & 0 & 0 & 0 & 0 \\
\hline n-Hexane & 86.177 & 0.4361 & 0.1362 & 0.4181 & 0.1395 \\
\hline Mcyclopentane & 84.16 & 0.058 & 0.0386 & 0.0563 & 0.0391 \\
\hline Benzene & 78.114 & 0.0198 & 0.0107 & 0.0191 & 0.0109 \\
\hline n-Heptane & 100.2 & 0.005 & 0.2217 & 0.005 & 0.2271 \\
\hline Ecyclopentane & 98.19 & 0.0007 & 0.0587 & 0.0007 & 0.0601 \\
\hline Toluene & 92.141 & 0.0002 & 0.0171 & 0.0002 & 0.0175 \\
\hline n-Octane & 114.23 & 0.0001 & 0.2248 & 0.0001 & 0.2303 \\
\hline C8 Naphtene & 112.2 & 0.0001 & 0.0775 & 0.0001 & 0.0794 \\
\hline E-Benzene & 106.17 & 0 & 0.0015 & 0 & 0.0015 \\
\hline Styrene & 104.15 & 0 & 0.0015 & 0 & 0.0015 \\
\hline p-Xylene & 106.17 & 0 & 0.003 & 0 & 0.003 \\
\hline m-Xylene & 106.17 & 0 & 0.0069 & 0 & 0.0071 \\
\hline o-Xylene & 106.17 & 0 & 0.0039 & 0 & 0.004 \\
\hline 224-Mhexane & 128.3 & 0 & 0.1581 & 0 & 0.162 \\
\hline C9 Aromatics & 120.2 & 0 & 0.007 & 0 & 0.0071 \\
\hline C10 Nonaromatic & 134.2 & 0 & 0.0094 & 0 & 0.0096 \\
\hline C10 Aromatics & 134.2 & 0 & 0 & 0 & 0 \\
\hline $\mathrm{H}_{2} \mathrm{O}$ & 18.015 & 0 & 0 & 0 & 0 \\
\hline Vapor & & 0 & 0 & 0 & 0 \\
\hline Temperature $\left[{ }^{\circ} \mathrm{C}\right]$ & & 47.06 & 212 & 149 & 235.6 \\
\hline Pressure [bar] & & 14.71 & 16.51 & 14.71 & 15.11 \\
\hline Molar Flow [kgmole/h] & & 1250 & 2250 & 1304 & 2196 \\
\hline Mass Flow $[\mathrm{kg} / \mathrm{h}]$ & & $8.24 \mathrm{E}+04$ & $2.35 \mathrm{E}+05$ & $8.42 \mathrm{E}+04$ & $2.34 \mathrm{E}+05$ \\
\hline Std Ideal Liq Vol Flow $\left[\mathrm{m}^{3} / \mathrm{h}\right]$ & & 129.2 & 329.2 & 132.6 & 325.8 \\
\hline Molar Enthalpy [kcal/kgmole] & & $-3.37 \mathrm{E}+04$ & $-3.99 \mathrm{E}+04$ & $-2.51 \mathrm{E}+04$ & $-3.86 \mathrm{E}+04$ \\
\hline Molar Entropy [kJ/kgmole-C] & & 83.19 & 223.5 & 173.2 & 240.7 \\
\hline Heat Flow $[\mathrm{kcal} / \mathrm{h}]$ & & $-4.22 \mathrm{E}+07$ & $-8.98 \mathrm{E}+07$ & $-3.27 \mathrm{E}+07$ & $-8.47 \mathrm{E}+07$ \\
\hline
\end{tabular}

condenser consume a lot of energy (30.6 Megawatts). The details of distillation tower of the naphtha treatment unit is reported in Table 1.

The Peng Robinson Equation of State (EoS) was used in simulation of distillation unit for calculating the vaporliquid equilibria and calculating the density of liquids for hydrocarbon systems (Peng and Robinson, 1976). Some modifications were done on the original Peng Robinson EoS to extend its applications and predict some unusual systems. Peng Robinson model solves every three-level or two-level or one-level system with high efficiency and reliance and it is practical in a vast area of conditions (Peng and Robinson, 1976). The distillation tower was modeled as a reboiler absorption column. Condenser is custom-made which is connected to the top of distillation tower. Software was solving method for distillation tower which is in-out loop. This method is suitable for all of the design purposes and allows the design engineer to add equipment like heat exchangers, mixers, pumps, separators, heaters and valves to the intended distillation tower. 


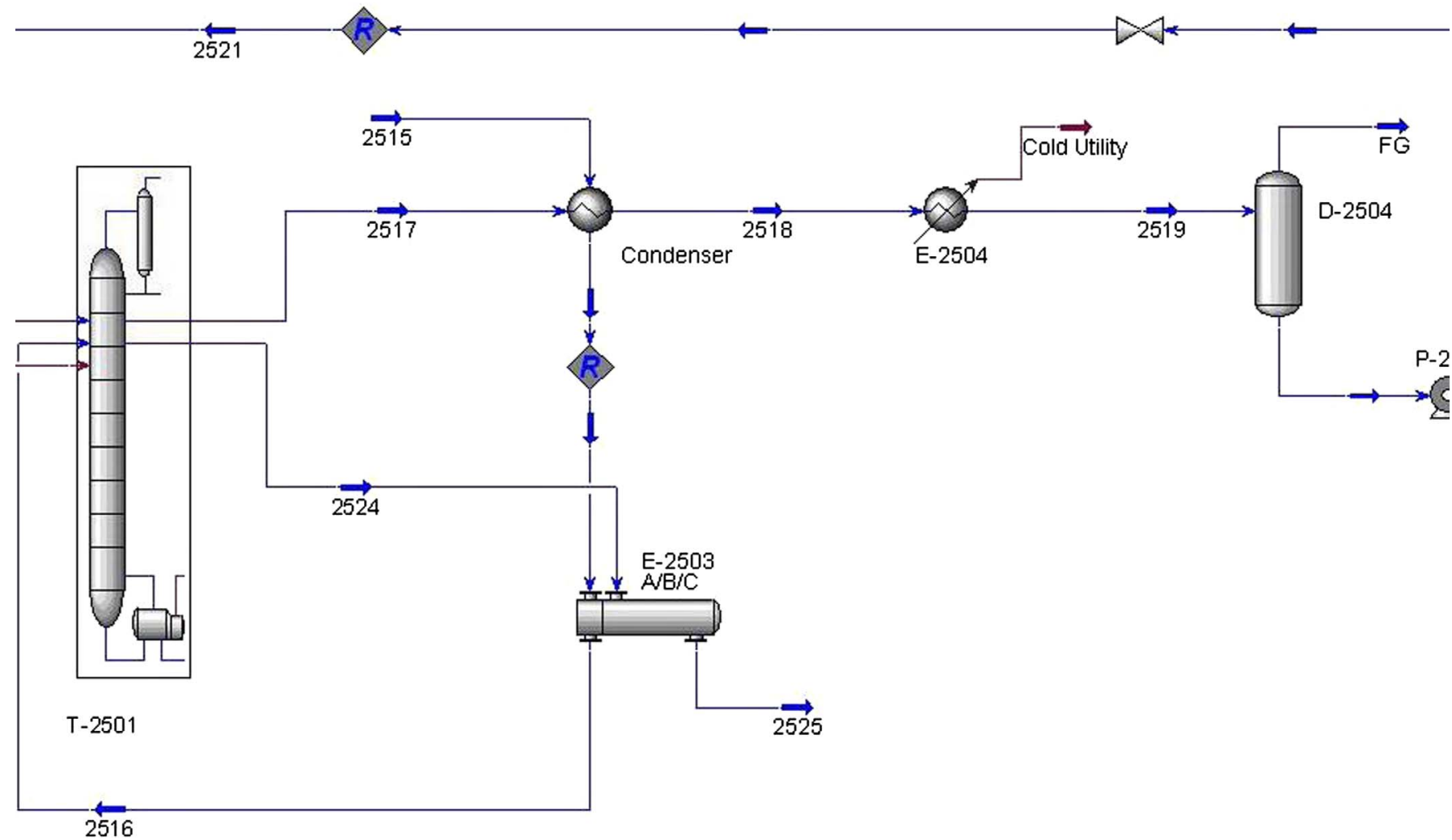

Fig. 2. Schematic of energy recovery by feed of the process.

\section{Results and discussion}

\subsection{Energy integration by feed stream (Energy efficiency scenario)}

This method of energy optimization is categorized as an innovative method of saving energy. It uses simple calculations. This method can save more than $40 \%$ of energy in a proper process. Incoming feed in stripping part of the purification unit is one of the cooling equipment that is used in the operational unit. The overhead vapor in tower is condensed in second stages, however the temperature of the incoming feed is suitable for the first stage of condensation in the AC. The schematic of using incoming feed for energy saving is shown in Figure 2.

Feed exchanges heat in second stages and its enthalpy is increased (Fig. 3a). Feed's second-stage enthalpy change is shown in Figure 3a. Feed's initial state consists of $\mathrm{T}_{1}$ temperature and $\mathrm{H}_{1}$ enthalpy that are changed to $\mathrm{T}_{2}$ and $\mathrm{H}_{2}$ in the condenser. By transferring heat from overhead vapor to feed, hot stream's temperature will be decreased without cooling, even more than the estimated amount. Finally, feed with $\mathrm{T}_{2}$ and $\mathrm{H}_{2}$ state goes in the main preheater (Heat exchanger 2503) and it reaches the final state $\left(\mathrm{T}_{3}, \mathrm{H}_{3}\right)$ by the secondary heat source (waste product) and goes in the distillation tower. Increasing the enthalpy of feed from $\mathrm{H}_{1}$ to $\mathrm{H}_{3}$ in addition to removing the $\mathrm{AC}$, decreases the energy consumption of reboiler (furnace 2502 ) up to $14.7 \%$ by increasing the temperature to $T_{3}$.

\subsection{Optimization analysis by composite pinch curve}

Correctly merging the pinch tools with process design before process engineering is very important. Choices made in this stage of design influence all equipment used in the process (Snoek and Tjoe, 1992). Using the pinch technology tools and understanding the process do not guarantee proper results. These tools need to be used in a convenient part of design stage. According to created composite curves and calculated executive objectives, it is rational that the process reformations should be in considerations before continuing the design. Shape of curve shows the potential for increasing heat recovery and actions needed to decrease external heat and chill.

In ideal state composite curves should be parallel so that the heat recovery is at maximum amount (Yoda and Shibuya, 1995). In fact composite curves have knots and knees that act as pinch points and heat recovery will be limited. One of the ways to make composite curves parallel is moving these knots to other heat degrees or removing these knots completely by focusing mainly on pinch point of the process. Having an area with heat shortage on the pinch process and an area with extra pinch under the process pinch provides instructions to correct the process to 


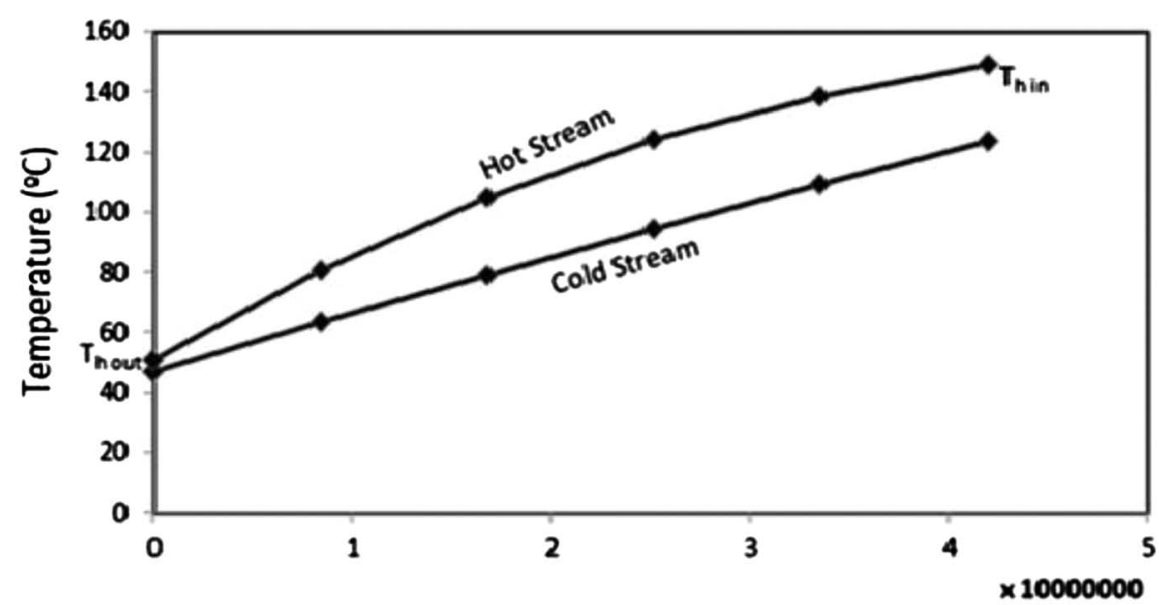

Heat Flow (kJ/h)

(a)

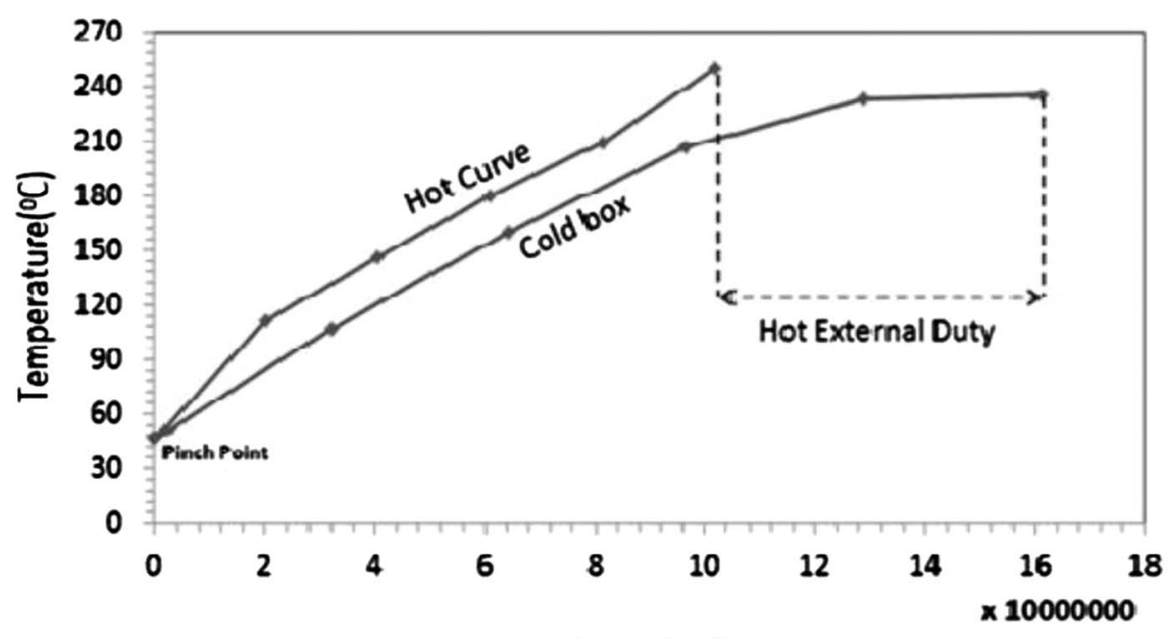

Heat Flow $(k J / h)$

(b)

Fig. 3. (a) Heat transfer in condenser after tower according to optimization, (b) pinch curve of naphtha treating unit after optimization.

increase potential of the heat recycling (Natori, 1992; Umeda et al., 1979). In Figure 3b, combined pinch curve for saving energy by feed is shown. Heat information such as source temperatures, sink temperature and enthalpy amount for drawing the Temperature-Enthalpy curve were derived from software. According to this figure, using feed for optimization leads to good effects on energy consumption by operational unit. A desirable overlap is made between hot and cold curves that is result of removing $\mathrm{AC}$ and decreasing the heat exchangers energy e-2504 (decreasing cold waters debit) and decreasing reboiler's heat load. According to Figure 3b, hot curve (heat source) is not completely overlapping the sink curve and it still needs heat utility. Previous descriptions were relevant to after the pinch point and because the feed supplied systems need to cold utility in Figure $3 \mathrm{~b}$ before the pinch point there is no enthalpy difference and amount of energy needed by system before the pinch is zero. As shown in Figure 4, several parameters such as feed temperature, reboiler energy efficiency, condensation energy, energy consumption, heat distribution and energy efficiency have been evaluated before and after optimization. The economic analysis of designed process was done by Aspen HYSYS software and results are shown in Table 2 . 


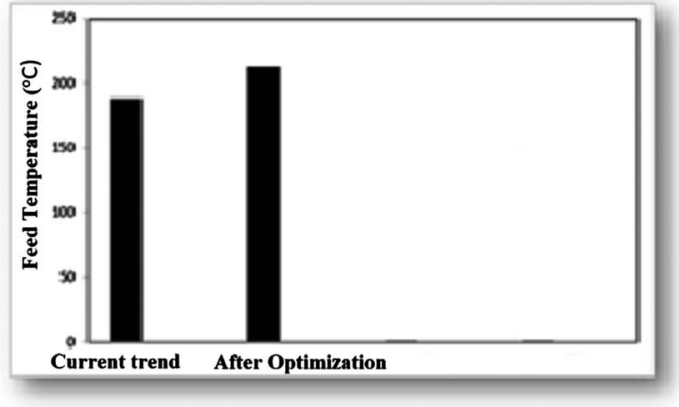

(a)

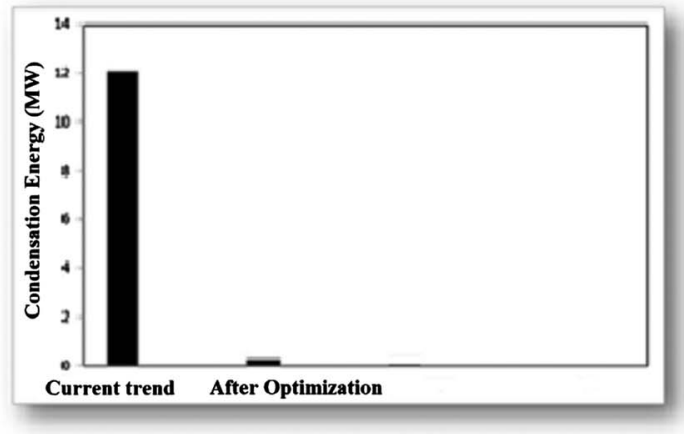

(c)

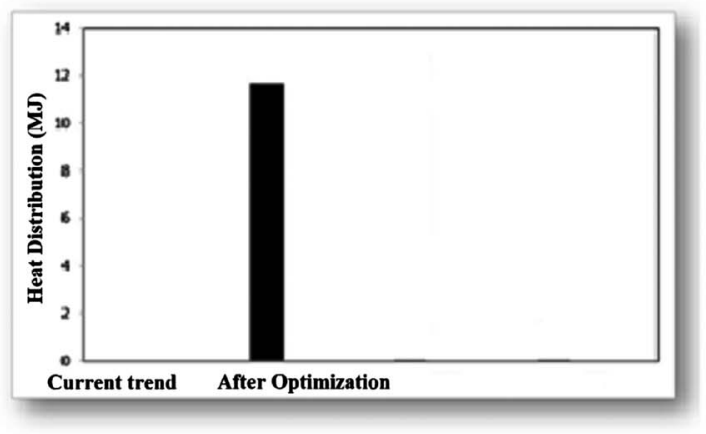

(e)

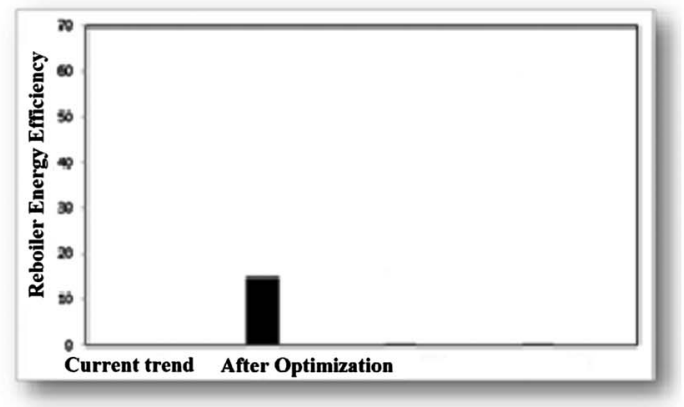

(b)

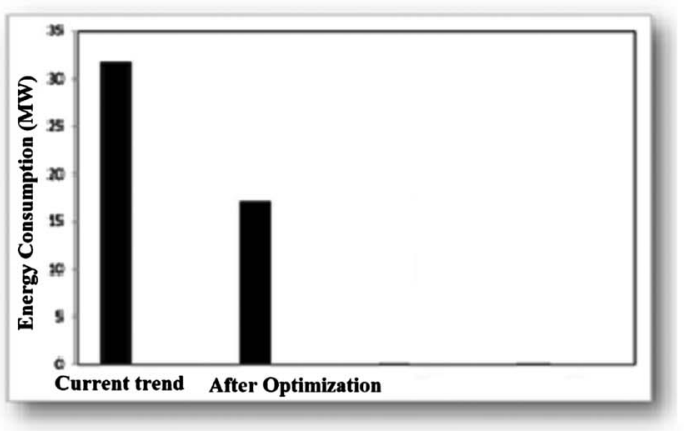

(d)

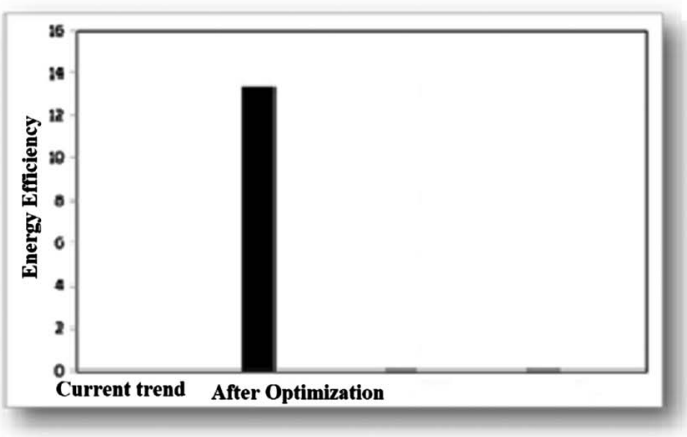

(f)

Fig. 4. Comparison several parameters before and after optimization. (a) Feed temperature, (b) reboiler energy efficiency, (c) condensation energy, (d) energy consumption, (e) heat distribution, (f) energy efficiency.

Table 2. Details of economic analysis after process optimization.

\begin{tabular}{lc}
\hline Type of cost & Value \\
\hline Total capital cost [USD] & 8047180 \\
Total operating cost [USD/Year] & 1134990 \\
Total raw materials cost [USD/Year] & 0 \\
Total product sales [USD/Year] & 0 \\
Total utilities cost [USD/Year] & 59264.1 \\
Desired rate of return [\%/Year] & 20 \\
P.O. period [Year] & 0 \\
Equipment cost [USD] & 1871700 \\
Total installed cost [USD] & 3407300 \\
\hline
\end{tabular}

\section{Conclusion}

In recent decades due to the ascending energy cost, energy optimization is of vital importance in petrochemical plants. Non-optimized energy consumption will cause a lot of problems including environmental problems (Morgan, 1992). With the efforts of experts a lot of ways were suggested to solve this dilemma. In this regard, several concepts, including process integration, were introduced and applied (Natori, 1992). In this work, naphtha purification unit (stripping part) of a petrochemical plant was optimized by using an energy recovery method. It affects both condenser and reboiler simultaneously. Gas fuel is burned in stripping part of tower's like a furnace. Hence, this optimization is effective for reducing the greenhouse effect 
caused by burning of hydrocarbons. Surveying the combined pinch curve shows that the chosen method reduces the utility usage before pinch point to approximate zero by using feed stream as cooling fluid and the separation process at top of the tower is completely integrated.

\section{References}

Amidpour M., Polley G. (1997) Application of problem decomposition in process integration, Chem. Eng. Res. Des $\mathbf{7 5}, \mathbf{1}$, 53-63.

Avenier P., Bazer-Bachi D., Bazer-Bachi F., Chizallet C., Deleau F., Diehl F., Gornay J., Lemaire É., Moizan-Basle V., Plais C., Raybaud P., Richard F., Lacombe S. (2016) Catalytic reforming: Methodology and process development for a constant optimisation and performance enhancement, Oil Gas Sci. Technol. - Rev. IFP Energies nouvelles 71, 3, 41.

Biegler L.T., Grossmann I.E., Westerberg A.W. (1997) Systematic methods for chemical process design, N. p., United States, Web.

Chang H., Shih C.M. (2005) Simulation and optimization for power plant flue gas $\mathrm{CO}_{2}$ absorption-stripping systems, Sep. Sci. Technol. 40, 4, 877-909.

Furman K.C., El-Bakry A.S., Song J.H. (2017) Optimization in the oil and gas industry, Optim. Eng. Springer, US 18, 1, 1-2.

Geankoplis C.J., Hersel A.A., Lepek D.H. (2018) Transport processes and separation process principles, Prentice Hall, New Jersey, USA.

Gerberich H.R., Seaman G.C. (1994) Formaldehyde: Encyclopedia of chemical technology, Vol. 11, Wiley, New York, USA.

Gong H.-F., Chen Z.S., Zhu Q.X., He Y.L. (2017) A Monte Carlo and PSO based virtual sample generation method for enhancing the energy prediction and energy optimization on small data problem: An empirical study of petrochemical industries, Appl. Energy 197, 405-415.

Gundersen T. (2000) A process integration primer - Implementing agreement on process integration, International Energy Agency, SINTEF Energy Research, Trondheim, Norway, pp. 34-47.

Jana A.K. (2017) A thermally coupled dividing tower batch rectifier: Energy consumption and cost, Appl. Therm. Eng. 119, 610-616.

Kamath R.S., Grossmann I.E., Biegler L.T. (2010) Aggregate models based on improved group methods for simulation and optimization of distillation systems, Comput. Chem. Eng. 34, 8, 1312-1319.

Kiran B., Jana A.K. (2015) Introducing vapor recompression mechanism in heat-integrated distillation column: Impact of internal energy driven intermediate and bottom reboiler, AIChE J. 61, 1, 118-131.

Manan Z.A., Mohd Nawi W.N.R., Wan Alwi S.R., Klemeš J.J. (2017) Advances in process integration research for
$\mathrm{CO}_{2}$ emission reduction - A review, J. Clean. Prod. 167, $1-13$.

Morgan S.W. (1992) Use process integration to improve process designs and the design process, Chem. Eng. Prog. 88, 9, 62-68.

Natori Y. (1992) Managing the implementation of pinch technology in a large company, IEA Workshop on Process Integration, Gottenburg, Sweden.

Ochoa-Estopier L.M., Jobson M., Smith R. (2014) The use of reduced models for design and optimisation of heat-integrated crude oil distillation systems, Energy 75, 5-13.

Peng D.-Y., Robinson D.B. (1976) A new two-constant equation of state, Ind. Eng. Chem. Fundam. 15, 1, 59-64.

Polley G., Heggs P. (1999) Don't let the pinch pinch you, Chem. Eng. Prog. 95, 12, 27-36.

Portha J.-F., Jaubert J.-N., Louret S., Pons M.-N. (2010) Life cycle assessment applied to naphtha catalytic reforming, Oil Gas Sci. Technol. - Rev. IFP Energies nouvelles 65, 5, 793-805.

Rossiter A., Spriggs H.D., Klee H. Jr (1993) Apply process integration to waste minimization, Chem. Eng. Prog. (United States), 89, 1.

Shafiee M., Jalali A., Mohammadi A.H., Amirhamzeh M. (2018) Simulation and energy optimization of the stabilizer tower of a pyrolysis gasoline hydrogenation unit, Energy Sources, Part A: Recovery, Utilization, and Environmental Effects, 40, 14, 1714-1720.

Skiborowski M., Recker S., Marquardt W. (2018) Shortcutbased optimization of distillation-based processes by a novel reformulation of the feed angle method, Chem. Eng. Res. Des. 132, 135-148.

Snoek J., Tjoe T. (1992) Process integration experience in a large company, IEA Workshop on Process Integration, Gottenburg, Sweden.

Tarjani A.J., Toth A.J., Nagy T., Haaz E., Valentinyi N., Andre A., Fozer D., Mizsey P. (2018) Thermodynamic and exergy analysis of energy-integrated distillation technologies focusing on dividing-wall columns with upper and lower partitions, Ind. Eng. Chem. Res. 57, 10, 3678-3684.

Tjoe T.N., Linnhoff B. (1986) Using pinch technology for process retrofit, Chem. Eng. 93, 8, 47-60.

Umeda T., Niida K., Shiroko K. (1979) A thermodynamic approach to heat integration in distillation systems, AIChE J. 25, 3, 423-429.

Yoda H., Shibuya H. (1995) An approach to minimum energy plant design incorporating pinch technology and state-of-theart equipment, National Petroleum Refiners Association, Washington, DC (United States).

Zhao H., Ierapetritou M.G., Shahn N.K., Rong G. (2017) Integrated model of refining and petrochemical plant for enterprise-wide optimization, Comput. Chem. Eng. 97, 194-207.

Zheng H., Li Y., Xu C. (2017) Control of Highly Heat-Integrated Energy-Efficient Extractive Distillation Processes, Ind. Eng. Chem. Res. 56, 19, 5618-5635. 